\title{
Effect of ambient air pollution on the incidence of appendicitis
}

\author{
Gilaad G. Kaplan MD MPH, Elijah Dixon MD MSc, Remo Panaccione MD, Andrew Fong MSc, \\ Li Chen MSc, Mieczyslaw Szyszkowicz PhD, Amanda Wheeler PhD, Anthony MacLean MD, \\ W. Donald Buie MD MSc, Terry Leung MD, Steven J. Heitman MD MSc, Paul J. Villeneuve PhD
}

Previously published at www.cmaj.ca

\section{ABSTRACT}

Background: The pathogenesis of appendicitis is unclear. We evaluated whether exposure to air pollution was associated with an increased incidence of appendicitis.

Methods: We identified 5191 adults who had been admitted to hospital with appendicitis between Apr. 1, 1999, and Dec. 31, 2006. The air pollutants studied were ozone, nitrogen dioxide, sulfur dioxide, carbon monoxide, and suspended particulate matter of less than $10 \mu$ and less than $2.5 \mu$ in diameter. We estimated the odds of appendicitis relative to short-term increases in concentrations of selected pollutants, alone and in combination, after controlling for temperature and relative humidity as well as the effects of age, sex and season.

Results: An increase in the interquartile range of the 5day average of ozone was associated with appendicitis (odds ratio [OR] 1.14, 95\% confidence interval [CI] 1.031.25). In summer (July-August), the effects were most pronounced for ozone (OR 1.32,95\% Cl 1.10-1.57), sulfur dioxide (OR 1.30, 95\% Cl 1.03-1.63), nitrogen dioxide (OR $1.76,95 \% \mathrm{Cl} 1.20-2.58$ ), carbon monoxide (OR 1.35, 95\% Cl 1.01-1.80) and particulate matter less than $10 \mu$ in diameter (OR 1.20, 95\% Cl 1.05-1.38). We observed a significant effect of the air pollutants in the summer months among men but not among women (e.g., OR for increase in the 5-day average of nitrogen dioxide 2.05, $95 \% \mathrm{Cl} 1.21-3.47$, among men and 1.48 , 95\% Cl $0.85-$ 2.59, among women). The double-pollutant model of exposure to ozone and nitrogen dioxide in the summer months was associated with attenuation of the effects of ozone (OR 1.22, 95\% Cl 1.01-1.48) and nitrogen dioxide (OR 1.48, 95\% Cl 0.97-2.24).

Interpretation: Our findings suggest that some cases of appendicitis may be triggered by short-term exposure to air pollution. If these findings are confirmed, measures to improve air quality may help to decrease rates of appendicitis.
A ppendicitis was introduced into the medical vernacu1 pathogenesis implicated an obstruction of the appendiceal orifice by a fecalith or lymphoid hyperplasia. ${ }^{2}$ However, this notion does not completely account for variations in incidence observed by age, ${ }^{3,4}$ sex,,${ }^{3,4}$ ethnic background, ${ }^{3,4}$ family history, ${ }^{5}$ temporal-spatial clustering ${ }^{6}$ and seasonality, ${ }^{3,4}$ nor does it completely explain the trends in incidence of appendicitis in developed and developing nations. ${ }^{37,8}$

The incidence of appendicitis increased dramatically in industrialized nations in the 19th century and in the early part of the 20th century. ${ }^{1}$ Without explanation, it decreased in the middle and latter part of the 20th century. ${ }^{3}$ The decrease coincided with legislation to improve air quality. For example, after the United States Clean Air Act was passed in 1970, ${ }^{9}$ the incidence of appendicitis decreased by $14.6 \%$ from 1970 to $1984 .{ }^{3}$ Likewise, a 36\% drop in incidence was reported in the United Kingdom between 1975 and $1994^{10}$ after legislation was passed in 1956 and 1968 to improve air quality and in the 1970s to control industrial sources of air pollution. Furthermore, appendicitis is less common in developing nations; however, as these countries become more industrialized, the incidence of appendicitis has been increasing.

Air pollution is known to be a risk factor for multiple conditions, to exacerbate disease states and to increase all-cause mortality. ${ }^{11}$ It has a direct effect on pulmonary diseases such as asthma ${ }^{11}$ and on nonpulmonary diseases including myocardial infarction, stroke and cancer. ${ }^{11-13}$ Inflammation induced by exposure to air pollution contributes to some adverse health effects. ${ }^{14-17}$ Similar to the effects of air pollution, a proinflammatory response has been associated with appendicitis. ${ }^{18-20}$

From the Division of Gastroenterology, Department of Medicine (Kaplan, Panaccione, Heitman), and the Departments of Community Health Sciences (Kaplan, Dixon) and Surgery (Dixon, MacLean, Buie, Leung), University of Calgary, Calgary, Alta.; Alberta Health Services (Fong), Edmonton, Alta.; the Air Health Science Division (Wheeler) and the Population Studies Division (Chen, Szyszkowicz, Villeneuve), Health Canada, Ottawa, Ont.; and the Dalla Lana School of Public Health (Villeneuve), University of Toronto, Toronto, Ont.

Cite as CMAJ 2009. DOI:10.1503/cmaj.082068 
We conducted a case-crossover study involving a population-based cohort of patients admitted to hospital with appendicitis to determine whether short-term increases in concentrations of selected air pollutants were associated with hospital admission because of appendicitis.

\section{Methods}

\section{Study design}

We used a case-crossover study design. This design is an adaptation of the case-control study, with cases serving as their own controls. ${ }^{21}$ For each case of appendicitis, we compared an exposure metric for the case event (the date of admission to hospital) with the same metric derived for the time-stratified matched control events (when no admission occurred). These metrics of exposures were: same-day exposure, exposure lagged by 1 day, and 3-day, 5-day and 7-day average before event. We chose these exposure metrics using a time-stratified design to avoid time trend biases. ${ }^{22}$ Also, we matched control events to case events by day of week to control for "day of week" effects. ${ }^{21}$ By design, our selection of these short-term referent intervals controlled for seasonal patterns in disease occurrence. Because we were making within-individual comparisons, there was no confounding by time-independent risk factors (e.g., smoking).

\section{Study population}

The Calgary Health Region is a fully integrated and publicly funded health care system in Canada's province of Alberta that serves over 1 million residents of Calgary. We identified a cohort of patients aged 18 years or older living in Calgary who were admitted to hospital between Apr. 1, 1999, and Dec. 31, 2006, using data from the Quality, Safety and Health Information administrative hospital discharge database. We defined an incident case of appendicitis as one that had a discharge diagnosis of appendicitis based on the International Classification of Diseases, 9th or 10th revision (ICD-9 code $540.9,540.0$ or 540.1 , or ICD-10 code K35.0, K35.1 or K35.9). We excluded cases with codes indicating unspecified or other appendicitis (e.g., chronic or recurrent), to minimize misclassification of appendectomies of a normal appendix and other causes of appendiceal disease. For each patient identified, we collected information on age at diagnosis (1834, 35-64 or $>64$ years), sex and date of hospital admission.

The study was approved by the Conjoint Health Research Ethics Board of the University of Calgary.

\section{Validation of study population}

We selected a subset of patients to validate the administrative definition of appendicitis. We used the discharge database to identify 1389 patients with ICD-9 codes $540.9,540.0$ or 540.1 between 1999 and 2002. We compared the administrative definition of appendicitis with the surgical pathology reports for these patients. We considered the administrative definition to be valid if at least $80 \%$ of the patients were shown to have appendicitis in the pathology report. Of the 1389 patients, $1177(84.7 \%)$ were accurately identified as having appendicitis according to the pathology report. The accuracy rate was greater among men $(87.7 \%)$ than among women $(81.3 \%)$. The pathology report for the remaining patients indicated a normal appendix, chronic or recurrent appendicitis, or some other cause (e.g., cancer).

\section{Measurement of exposure to air pollution}

Environment Canada's National Air Pollution Surveillance Network monitors more than 152 stations in 55 cities across Canada, including 3 dedicated sites in Calgary. The air pollutants monitored at these stations include ozone, nitrogen dioxide, sulfur dioxide, carbon monoxide, and suspended particles with aerodynamic diameters of less than $10 \mu$ and less than $2.5 \mu$. Automated fixed-site continuous-monitoring stations collect hourly mean concentrations that are used to calculate daily mean and maximum values. ${ }^{12}$

For each case of appendicitis, the daily maximum for ozone and the daily means for the other pollutants were determined. We obtained data for daily mean temperature and relative humidity from Environment Canada. The frequency distribution of the daily mean concentrations of the pollutants and the weather parameters, stratified by season, during the study period are presented in Appendix 1 (available at www .cmaj.ca/cgi/content/full/cmaj.082068/DC1). The correlations between these variables are provided in Appendix 2 (available at www.cmaj.ca/cgi/content/full/cmaj.082068/DC1) .

\section{Statistical analysis}

We explored the association between appendicitis and air pollution using single-pollutant models. We stratified our analyses by age, sex and season. We defined the seasons as follows: spring, March-May; summer, June-August; autumn, September-November; and winter, December-February. We used the 1-day lag and the 3-, 5- and 7-day averages before hospital admission to account for delays in onset of appendicitis and presentation to hospital. We also chose the 3-, 5and 7-day averages to evaluate the cumulative effects of pollution concentrations that persisted for several days. For the summer months, we explored the combined effects of air pollutants using double-pollutant models to control for correlated exposures of co-pollutants. In addition, we explored differential effects of age and sex in the summer months.

We calculated odds ratios (ORs) with 95\% confidence intervals (CIs) to evaluate the association between appendicitis and an increase in the interquartile range of the daily maximum of ozone and the daily mean concentrations of the other pollutants during the different time intervals. We adjusted odds ratios for temperature and relative humidity. We calculated the interquartile ranges on the basis of the daily mean concentrations of the pollutants reported in Appendix 1 (available at www.cmaj.ca/cgi/content/full/cmaj.082068/DC1).

\section{Results}

We identified 5191 adult patients admitted to hospital with appendicitis during the study period. Most were aged between 18 and 35 years (46.3\%), were men (53.2\%) and were admitted on a weekday (71.5\%). Most of the hospital admissions occurred between April and September (52.5\%). 
Associations between ambient air pollutants and appendicitis, stratified by season, are shown in Table 1 . Increases in the interquartile range of the daily maximum for ozone and the daily mean concentration for the other pollutants on the same day as the case event or the day before hospital admission were not associated with an increased risk of appendicitis. When we analyzed the increases in interquartile ranges of the 5- and 7-day averages, exposures to ozone and sulfur dioxide were significantly associated with appendicitis (e.g., OR for 7-day average 1.15, 95\% CI 1.04-1.28, for ozone and $1.13,95 \%$ CI $1.02-1.25$, for sulfur dioxide). The magnitude of effect of each air pollutant increased markedly during the summer months. For example, the risk estimate for the 5-day average of nitrogen dioxide increased from 1.11 (95\% CI $1.00-1.24)$ in all seasons to 1.76 (95\% CI 1.20-2.58) in summer (Table 1).

When we analyzed the data by age and sex, we found that the effect of ozone was significant among patients aged 3564 years (OR for 5-day average 1.21, 95\% CI 1.05-1.39; for 7-day average 1.17, 95\% CI 1.01-1.37) and among men (OR for 5-day average 1.19, 95\% CI 1.04-1.36; for 7-day average $1.22,95 \%$ CI 1.06-1.41). In addition, the effects were significant for particulate matter less than $2.5 \mu$ among patients aged 18-34 years (OR for 5-day average 1.07, 95\% CI 1.01-1.14;

Table 1: Risk of appendicitis associated with increases in the interquartile range of pollutants during various referrant time intervals, by season*

\begin{tabular}{|c|c|c|c|c|c|c|}
\hline \multirow[b]{2}{*}{ Pollutant† } & \multirow[b]{2}{*}{ Time interval¥ } & \multicolumn{5}{|c|}{ Season; OR $(95 \% \mathrm{CI}) \S$} \\
\hline & & $\begin{array}{c}\text { All seasons } \\
n=5191\end{array}$ & $\begin{array}{c}\text { Spring } \\
n=1301\end{array}$ & $\begin{array}{l}\text { Summer } \\
n=1369\end{array}$ & $\begin{array}{l}\text { Autumn } \\
n=1391\end{array}$ & $\begin{array}{l}\text { Winter } \\
n=1130\end{array}$ \\
\hline \multirow[t]{5}{*}{ Ozone } & Same day & $1.05(0.98-1.13)$ & $1.15(0.96-1.38)$ & $0.95(0.83-1.09)$ & $1.08(0.93-1.25)$ & $1.11(0.94-1.30)$ \\
\hline & 1-day lag & $1.06(0.99-1.13)$ & $0.90(0.78-1.05)$ & $1.10(0.97-1.24)$ & $1.13(1.01-1.28)$ & $1.07(0.93-1.22)$ \\
\hline & 3-day average & $1.10(1.01-1.20)$ & $0.96(0.77-1.20)$ & $1.14(0.96-1.34)$ & $1.13(0.95-1.33)$ & $1.15(0.95-1.40)$ \\
\hline & 5-day average & $1.14(1.03-1.25)$ & $1.05(0.83-1.32)$ & 1.32 (1.10-1.57) & $1.09(0.91-1.30)$ & $1.09(0.87-1.36)$ \\
\hline & 7-day average & $1.15(1.04-1.28)$ & $1.07(0.84-1.37)$ & $1.33(1.10-1.61)$ & $1.08(0.90-1.30)$ & $1.08(0.96-1.20)$ \\
\hline \multirow[t]{5}{*}{ Sulfur dioxide } & Same day & $1.05(0.99-1.11)$ & $1.06(0.93-1.20)$ & $1.14(0.99-1.32)$ & $1.05(0.96-1.15)$ & $1.00(0.91-1.11)$ \\
\hline & 1-day lag & $1.00(0.94-1.06)$ & $0.99(0.86-1.13)$ & $1.15(1.00-1.33)$ & $0.99(0.90-1.10)$ & $0.95(0.86-1.05)$ \\
\hline & 3-day average & $1.06(0.98-1.15)$ & $1.10(0.92-1.32)$ & $1.30(1.07-1.59)$ & $1.06(0.93-1.21)$ & $0.96(0.84-1.10)$ \\
\hline & 5-day average & $1.10(1.00-1.20)$ & $1.19(0.95-1.47)$ & $1.30(1.03-1.63)$ & $1.08(0.93-1.27)$ & $1.01(0.86-1.18)$ \\
\hline & 7-day average & $1.13(1.02-1.25)$ & $1.20(0.94-1.54)$ & $1.36(1.05-1.75)$ & $1.11(0.92-1.34)$ & $1.03(0.87-1.23)$ \\
\hline \multirow{5}{*}{$\begin{array}{l}\text { Nitrogen } \\
\text { dioxide }\end{array}$} & Same day & $1.02(0.96-1.09)$ & $1.03(0.90-1.18)$ & $1.09(0.87-1.36)$ & $1.02(0.90-1.15)$ & $1.01(0.91-1.13)$ \\
\hline & 1-day lag & $0.98(0.92-10.5)$ & $0.95(0.83-1.09)$ & $1.16(0.93-1.45)$ & $0.97(0.86-1.10)$ & $0.96(0.86-1.08)$ \\
\hline & 3-day average & $1.04(0.95-1.14)$ & $0.97(0.81-1.17)$ & $1.33(0.96-1.84)$ & $1.07(0.91-1.26)$ & $1.01(0.87-1.18)$ \\
\hline & 5-day average & $1.11(1.00-1.24)$ & $1.06(0.85-1.32)$ & $1.76(1.20-2.58)$ & $1.07(0.88-1.30)$ & $1.08(0.91-1.30)$ \\
\hline & 7-day average & $1.12(0.99-1.13)$ & $1.04(0.81-1.35)$ & $1.87(1.21-2.90)$ & $1.08(0.88-1.34)$ & $1.08(0.87-1.33)$ \\
\hline \multirow{5}{*}{$\begin{array}{l}\text { Carbon } \\
\text { monoxide }\end{array}$} & Same day & $1.00(0.97-1.04)$ & $1.06(0.95-1.20)$ & $1.02(0.86-1.22)$ & $0.97(0.92-1.04)$ & $1.01(0.97-1.06)$ \\
\hline & 1-day lag & $0.99(0.96-1.03)$ & $1.02(0.91-1.14)$ & $1.08(0.91-1.28)$ & $0.98(0.91-1.04)$ & $0.99(0.94-1.04)$ \\
\hline & 3-day average & $1.01(0.96-1.07)$ & $1.05(0.90-1.23)$ & $1.12(0.88-1.44)$ & $1.00(0.92-1.10)$ & $1.00(0.93-1.08)$ \\
\hline & 5-day average & $1.06(1.00-1.13)$ & $1.13(0.94-1.35)$ & $1.35(1.01-1.80)$ & $1.01(0.91-1.13)$ & $1.07(0.98-1.16)$ \\
\hline & 7-day average & $1.05(0.99-1.13)$ & $1.11(0.88-1.41)$ & $1.35(0.98-1.87)$ & $1.12(0.92-1.37)$ & $1.05(0.95-1.15)$ \\
\hline \multirow{5}{*}{$\begin{array}{l}\text { Particulate } \\
\text { matter }<2.5 \mu \\
\text { in diameter }\end{array}$} & Same day & $1.01(0.98-1.04)$ & $1.04(0.95-1.12)$ & $1.01(0.96-1.06)$ & $1.02(0.96-1.08)$ & $1.00(0.93-1.07)$ \\
\hline & 1-day lag & $1.01(0.98-1.04)$ & $0.99(0.92-1.07)$ & $1.02(0.98-1.07)$ & $0.98(0.92-1.05)$ & $1.01(0.94-1.07)$ \\
\hline & 3-day average & $1.02(0.99-1.06)$ & $1.03(0.93-1.13)$ & $1.04(0.98-1.10)$ & $1.00(0.93-1.08)$ & $1.02(0.93-1.11)$ \\
\hline & 5-day average & $1.04(1.00-1.08)$ & $0.99(0.89-1.11)$ & $1.06(1.00-1.13)$ & $1.02(0.94-1.11)$ & $1.07(0.97-1.19)$ \\
\hline & 7-day average & $1.04(1.00-1.09)$ & $0.98(0.86-1.11)$ & $1.06(0.99-1.13)$ & $1.04(0.95-1.21)$ & $1.08(0.96-1.21)$ \\
\hline \multirow{5}{*}{$\begin{array}{l}\text { Particulate } \\
\text { matter }<10 \mu \\
\text { in diameter }\end{array}$} & Same day & $1.04(1.00-1.09)$ & $1.05(0.95-1.15)$ & $1.09(0.98-1.20)$ & $1.02(0.94-1.11)$ & $1.02(0.95-1.10)$ \\
\hline & 1-day lag & $1.02(0.97-1.06)$ & $0.97(0.89-1.06)$ & $1.05(0.96-1.16)$ & $0.98(0.90-1.07)$ & $1.05(0.97-1.13)$ \\
\hline & 3-day average & $1.05(0.99-1.11)$ & $0.99(0.88-1.12)$ & $1.15(1.01-1.30)$ & $1.02(0.92-1.13)$ & $1.05(0.94-1.17)$ \\
\hline & 5-day average & $1.07(1.00-1.13)$ & $0.95(0.82-1.10)$ & $1.20(1.05-1.38)$ & $1.05(0.94-1.18)$ & $1.06(0.94-1.20)$ \\
\hline & 7-day average & $1.06(0.99-1.14)$ & $0.90(0.76-1.06)$ & $1.20(1.03-1.39)$ & $1.07(0.95-1.21)$ & $1.05(0.92-1.20)$ \\
\hline
\end{tabular}

Note: $\mathrm{Cl}$ = confidence interval, $\mathrm{OR}=$ odds ratio.

*We defined spring as March-May, summer as June-August, autumn as September-November and winter as December-February.

†The daily maximum was determined for ozone; the daily means were determined for the other pollutants.

fFor each case of appendicitis, we compared the patient's exposure on the date of the case event (the date of admission to hospital because of appendicitis) with his or her exposure during time intervals that were close to the date of the case event. The 1-day lag, and the 3-, 5- and 7-day averages represent the periods before hospital admission.

§Odds ratios are adjusted for temperature and relative humidity. 
for 7-day average 1.08, 95\% CI 1.01-1.16) and for sulfur dioxide among men (OR for 5-day average 1.15, 95\% CI 1.01-1.30) (see Appendix 3, available at www.cmaj.ca/cgi /content/full/cmaj.082068/DC1).

When we restricted the analysis to data for the summer months, we observed pronounced differential effects across age and sex groups for all 6 pollutants (Table 2). Men, but not women, were consistently at increased risk of appendicitis during the summer. For example, an increase in the interquartile range of the 5-day average of nitrogen dioxide was significantly associated with appendicitis among men (OR 2.05, 95\% CI 1.21-3.47) but not among women (OR 1.48, 95\% CI 0.85-
2.59). Younger individuals (age 18-34 years) were more likely than older individuals to have appendicitis on days of higher concentrations of ozone (e.g., OR for 5-day average 1.39, 95\% CI 1.06-1.81) and particulate matter less than $10 \mu$ (e.g., OR for 5-day average 1.29, 95\% CI 1.05-1.59). The opposite was true for exposure to nitrogen dioxide, with the risk of appendicitis increasing with age (OR for 5-day average 2.07, 95\% CI 1.17-3.63, among patients 35-64 years; and 3.79, 95\% CI $1.03-14.01$, among patients $>64$ years) (Table 2 ).

In the double-pollutant models based on 5-day averages in the summer months, we found that exposure to ozone and nitrogen dioxide remained significantly associated with

Table 2: Risk of appendicitis associated with increases in the interquartile range of pollutants in summer during various referrant time intervals, by age and sex*

\begin{tabular}{|c|c|c|c|c|c|c|}
\hline \multirow[b]{2}{*}{ Pollutant† } & \multirow[b]{2}{*}{ Time interval¥ } & \multicolumn{3}{|c|}{ Age group, yr; OR $(95 \% \mathrm{Cl}) \S$} & \multicolumn{2}{|c|}{ Sex; OR $(95 \% \mathrm{CI}) \S$} \\
\hline & & $\begin{array}{c}18-34 \\
n=618\end{array}$ & $\begin{array}{c}35-64 \\
n=630\end{array}$ & $\begin{array}{c}>64 \\
n=121\end{array}$ & $\begin{array}{l}\text { Female } \\
n=638\end{array}$ & $\begin{array}{c}\text { Male } \\
n=731\end{array}$ \\
\hline \multirow[t]{5}{*}{ Ozone } & Same day & $1.04(0.85-1.27)$ & $0.87(0.71-1.07)$ & $0.93(0.58-1.50)$ & $0.89(0.73-1.09)$ & $1.00(0.83-1.21)$ \\
\hline & 1-day lag & $1.11(0.93-1.33)$ & $1.11(0.93-1.33)$ & $0.94(0.62-1.43)$ & $1.08(0.90-1.29)$ & $1.11(0.94-1.31)$ \\
\hline & 3-day average & $1.20(0.94-1.53)$ & $1.09(0.86-1.40)$ & $1.04(0.60-1.82)$ & $1.11(0.87-1.41)$ & $1.16(0.93-1.46)$ \\
\hline & 5-day average & $1.39(1.06-1.81)$ & $1.29(0.99-1.68)$ & $1.10(0.62-1.96)$ & $1.19(0.92-1.55)$ & $1.43(1.12-1.82)$ \\
\hline & 7-day average & $1.50(1.13-2.01)$ & $1.26(0.94-1.67)$ & $0.94(0.49-1.80)$ & $1.13(0.86-1.50)$ & $1.53(1.17-2.00)$ \\
\hline \multirow[t]{5}{*}{ Sulfur dioxide } & Same day & $0.99(0.79-1.23)$ & $1.37(1.10-1.70)$ & $0.96(0.59-1.57)$ & $1.03(0.83-1.27)$ & $1.26(1.03-1.54)$ \\
\hline & 1-day lag & $1.09(0.88-1.34)$ & $1.11(0.90-1.38)$ & $1.85(1.14-2.99)$ & $1.20(0.98-1.47)$ & $1.11(0.91-1.36)$ \\
\hline & 3-day average & $1.14(0.84-1.53)$ & $1.40(1.04-1.90)$ & $1.77(0.93-3.40)$ & $1.15(0.87-1.53)$ & $1.48(1.11-1.96)$ \\
\hline & 5-day average & $1.03(0.73-1.46)$ & $1.47(1.04-2.07)$ & $2.03(0.98-4.23)$ & $1.01(0.73-1.40)$ & $1.68(1.21-2.34)$ \\
\hline & 7-day average & $1.16(0.80-1.70)$ & $1.44(0.98-2.12)$ & $2.08(0.92-4.68)$ & $1.12(0.78-1.60)$ & $1.67(1.16-2.40)$ \\
\hline \multirow{5}{*}{$\begin{array}{l}\text { Nitrogen } \\
\text { dioxide }\end{array}$} & Same day & $1.03(0.74-1.44)$ & $1.04(0.75-1.44)$ & $1.68(0.81-3.51)$ & $1.13(0.81-1.57)$ & $1.06(0.79-1.43)$ \\
\hline & 1-day lag & $1.15(0.83-1.61)$ & $0.97(0.70-1.33)$ & $3.35(1.53-7.34)$ & $1.13(0.81-1.55)$ & $1.20(0.89-1.62)$ \\
\hline & 3-day average & $1.07(0.66-1.74)$ & $1.25(0.78-2.01)$ & $4.75(1.61-14.02)$ & $1.28(0.80-2.05)$ & $1.38(0.89-2.15)$ \\
\hline & 5-day average & $1.28(0.72-2.26)$ & $2.07(1.17-3.63)$ & $3.79(1.03-14.01)$ & $1.48(0.85-2.59)$ & $2.05(1.21-3.47)$ \\
\hline & 7-day average & $1.60(0.83-3.06)$ & $1.84(0.96-3.52)$ & $4.37(0.98-19.50)$ & $1.38(0.73-2.64)$ & $2.41(1.32-4.39)$ \\
\hline \multirow{5}{*}{$\begin{array}{l}\text { Carbon } \\
\text { monoxide }\end{array}$} & Same day & $1.14(0.89-1.47)$ & $0.92(0.70-1.19)$ & $0.94(0.52-1.71)$ & $1.06(0.82-1.38)$ & $0.99(0.78-1.25)$ \\
\hline & 1-day lag & $1.18(0.91-1.52)$ & $0.94(0.73-1.22)$ & $1.37(0.76-2.44)$ & $0.93(0.72-1.20)$ & $1.22(0.97-1.55)$ \\
\hline & 3-day average & $1.20(0.82-1.73)$ & $0.99(0.69-1.43)$ & $1.48(0.66-3.34)$ & $0.96(0.67-1.38)$ & $1.28(0.92-1.80)$ \\
\hline & 5-day average & $1.37(0.89-2.11)$ & $1.26(0.82-1.92)$ & $1.74(0.67-4.50)$ & $1.06(0.69-1.60)$ & $1.68(1.13-2.50)$ \\
\hline & 7-day average & $1.52(0.93-2.46)$ & $1.18(0.74-1.90)$ & $1.52(0.53-4.33)$ & $0.98(0.61-1.57)$ & $1.79(1.15-2.79)$ \\
\hline \multirow{5}{*}{$\begin{array}{l}\text { Particulate } \\
\text { matter }<2.5 \mu \\
\text { in diameter }\end{array}$} & Same day & $1.04(0.98-1.11)$ & $0.96(0.89-1.04)$ & $1.00(0.80-1.26)$ & $1.01(0.94-1.08)$ & $1.01(0.94-1.08)$ \\
\hline & 1-day lag & $1.07(1.00-1.15)$ & $0.98(0.91-1.06)$ & $0.98(0.84-1.15)$ & $1.01(0.94-1.09)$ & $1.03(0.97-1.10)$ \\
\hline & 3-day average & $1.10(1.01-1.19)$ & $0.99(0.91-1.09)$ & $0.99(0.80-1.22)$ & $1.03(0.95-1.12)$ & $1.05(0.97-1.14)$ \\
\hline & 5-day average & $1.13(1.02-1.24)$ & $1.01(0.92-1.11)$ & $1.03(0.84-1.27)$ & $1.03(0.94-1.14)$ & $1.09(1.00-1.19)$ \\
\hline & 7-day average & $1.12(1.01-1.25)$ & $1.00(0.90-1.12)$ & $1.04(0.83-1.31)$ & $1.02(0.92-1.13)$ & $1.09(0.99-1.20)$ \\
\hline \multirow{5}{*}{$\begin{array}{l}\text { Particulate } \\
\text { matter }<10 \mu \\
\text { in diameter }\end{array}$} & Same day & $1.11(0.96-1.29)$ & $1.00(0.86-1.17)$ & $1.47(1.01-2.14)$ & $1.08(0.93-1.25)$ & $1.10(0.95-1.26)$ \\
\hline & 1-day lag & $1.14(0.98-1.32)$ & $0.97(0.84-1.12)$ & $1.05(0.76-1.46)$ & $1.02(0.88-1.18)$ & $1.08(0.95-1.24)$ \\
\hline & 3-day average & $1.23(1.02-1.48)$ & $1.04(0.86-1.25)$ & $1.29(0.84-1.99)$ & $1.04(0.86-1.25)$ & $1.25(1.05-1.49)$ \\
\hline & 5-day average & $1.29(1.05-1.59)$ & $1.10(0.90-1.34)$ & $1.30(0.82-2.06)$ & $1.04(0.85-1.27)$ & $1.36(1.13-1.64)$ \\
\hline & 7-day average & $1.33(1.07-1.66)$ & $1.06(0.85-1.31)$ & $1.33(0.81-2.20)$ & $1.01(0.81-1.26)$ & 1.39 (1.14-1.70) \\
\hline
\end{tabular}

Note: $\mathrm{Cl}=$ confidence interval, $\mathrm{OR}=$ odds ratio

*Summer = June-August.

†The daily maximum was determined for ozone; the daily means were determined for the other pollutants.

fFor each case of appendicitis, we compared the patient's exposure on the date of the case event (the date of admission to hospital because of appendicitis) with his or her exposure during time intervals that were close to the date of the case event. The 1-day lag, and the 3-, 5- and 7-day averages represent the periods before hospital admission.

§Odds ratios are adjusted for temperature and relative humidity 
appendicitis for most combined models (Figure 1). The combined model of ozone and nitrogen dioxide attenuated the effects of ozone (OR 1.22, 95\% CI 1.01-1.48) and nitrogen dioxide (OR 1.48, 95\% CI 0.97-2.24).

\section{Interpretation}

We found that the incidence of appendicitis was significantly associated with short-term exposure to air pollution. The effect of air pollution was greatest in the summer months, when individuals were most likely to be outside and exposure estimates from fixed-site monitors better reflected an individual's exposure. In the double-pollutant models, we found that exposure to ozone and nitrogen dioxide was the primary risk factor in the summer. Our findings are robust because the study was population-based, was well powered and used a validated case definition. Also, we controlled for potential confounders through the use of a case-crossover study design, adjusted for meteorologic effects and selected referent time intervals using a time-stratified approach. If our findings are substantiated, this novel association may in part explain the trends in the incidence of appendicitis in industrialized nations.

Prior studies reported nonsignificant associations between air pollution and appendicitis. ${ }^{23,24}$ However, the findings of those studies should be interpreted cautiously. The authors used a broad definition of appendicitis. For example, they included ICD-9 code 542 ("other appendicitis including chronic"), which would include false cases of appendicitis and thus make it more difficult to identify an association. In addition, they did not measure a cumulative average of exposure to air pollution.

We found that the association between air pollution and appendicitis was greatest during the summer months. This finding is consistent with results from prior studies that reported higher incidence of appendicitis in the summer. ${ }^{3,4}$ Air pollution has also been shown to have a seasonal health effect (e.g., on stroke). ${ }^{12}$ The significant associations that we observed in the summer were likely due to increased exposure to air pollutants from spending more time outdoors and leaving windows open..$^{25}$

In the summer months, ozone and nitrogen dioxide remained significantly associated with appendicitis in most of the double-pollutant models. However, the combined effects of nitrogen dioxide and ozone led to attenuation of effect estimates and loss of significance for nitrogen dioxide. This was likely secondary to collinearity between the measurements of the 2 pollutants (Appendix 2), because nitrogen oxide from traffic scavenges ozone. ${ }^{26}$ Nitrogen dioxide primarily arises from the combustion of fossil fuel in automobiles and is an important source of air pollution in urban settings. ${ }^{9}$ In contrast, ozone is a regional pollutant that typically forms when photochemical reactions occur at ground level with air pollution. ${ }^{9}$ During the summer, young adults were more likely than older individuals to have appendicitis after exposure to ozone, whereas older adults were more likely than young adults to have appendicitis after exposure to nitrogen dioxide. Differential susceptibility or sources of exposure to ozone and nitrogen dioxide by age may explain these findings; however, future studies are required to explore these age-specific effects.

For unexplained reasons men are more likely than women to have appendicitis. ${ }^{3.4}$ In our study, we found that increases in air pollution concentrations were strongly associated with

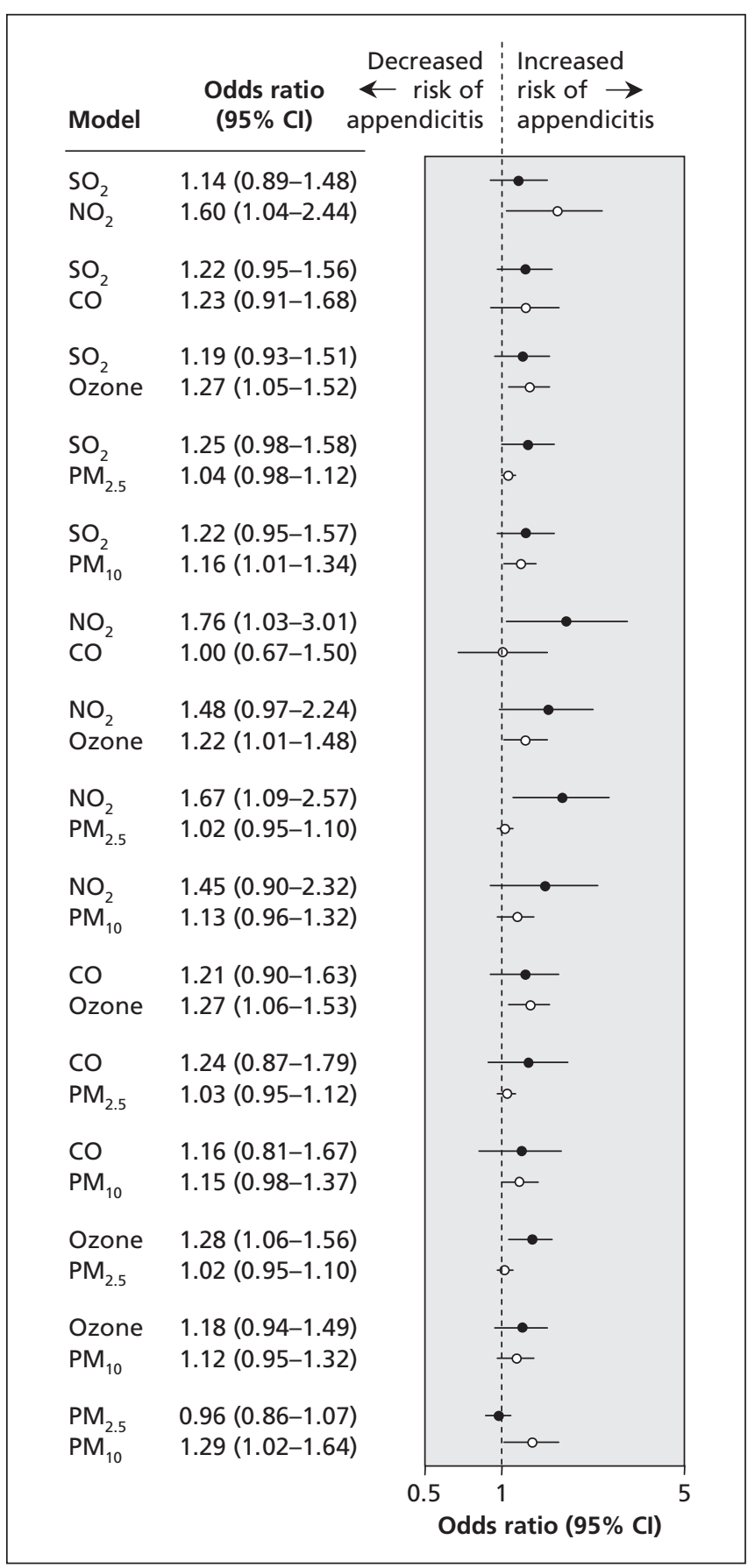

Figure 1: Double-pollutant model, showing associations between appendicitis and increases in the interquartile range of the 5-day average of pairs of air pollutants in summer (JuneAugust). Odds ratios are adjusted for temperature and relative humidity; values above 1.0 indicate an increased risk of appendicitis. Note: $\mathrm{SO}_{2}=$ sulfur dioxide, $\mathrm{NO}_{2}=$ nitrogen dioxide, $\mathrm{CO}=$ carbon monoxide, $\mathrm{PM}_{10}$ or $\mathrm{PM}_{2.5}=$ suspended particulate matter of less than $10 \mu$ or less than $2.5 \mu$ in diameter. 
appendicitis among men, but not among women. Men may be more susceptible to the effects of outdoor air pollution because they are more likely to be employed in outdoor occupations (e.g., roadwork). However, misclassification of appendicitis may also explain why the estimates were only significant among men. In the subset of patients we selected to validate the administrative definition of appendicitis, the accuracy of ICD-9 coding was higher among men $(87.7 \%)$ than among women $(81.3 \%)$.

The mechanisms by which air pollution may increase the risk of appendicitis are unknown. A pro-inflammatory response occurs with appendicitis that includes expression of cytokines such as tumour necrosis factor. ${ }^{19}$ In one study, inhalation of diesel exhaust by healthy volunteers was found to lead to increased levels of tumour necrosis factor. ${ }^{17}$ Exposure to ozone has been shown to activate tumour necrosis factor in animals and human cell lines. ${ }^{14,15}$ Animals fed diesel particles experienced oxidative damage in colonic mucosa. ${ }^{27}$ Therefore, exposure to air pollutants, either through inhalation or ingestion, may induce inflammatory responses that are also evident in appendicitis. Alternatively, exposure to diesel exhaust has been shown to increase susceptibility to bacterial $^{28}$ and viral ${ }^{29}$ pulmonary infections through impairment of microbial defence. ${ }^{30}$ If air pollution similarly affects gastrointestinal immunity, exposure to pollutants may increase the risk of bacterial invasion resulting in appendicitis.

\section{Limitations}

Our study has several limitations. First, we determined levels of exposure to air pollution on the basis of regional estimates from fixed-site monitoring stations, which cannot account for variability at the patient level.

Second, more than $15 \%$ of the cases in the administrative discharge database were misclassified as incident appendicitis. In addition, dates of hospital admission may have differed from dates of disease onset, because nearly $20 \%$ of patients with appendicitis delay presentation to hospital. ${ }^{31}$ Consequently, nondifferential misclassification may have led to nonsignificant estimates, particularly in association with exposure periods of the same day and 1-day lag.

Third, we did not evaluate the effects of air pollution on appendicitis among pediatric patients. This population is important, because children have a higher incidence of appendicitis and spend more time outdoors in the summer compared with adults.

Fourth, the effect size of the risk estimates were modest, and residual confounding may have introduced bias into our estimates. Data on potential confounders such as smoking and occupational exposures were lacking. However, because each patient essentially served as his or her own control, these factors would not be a source of bias. In contrast, unknown time-dependent risk factors of appendicitis may have not been controlled.

Finally, air-pollution studies are limited by multiple comparisons. Associations between air pollution and health outcomes are often explored with multiple pollutants using several lagged exposures. Frequently, analyses are stratified to investigate factors that may modify effects of air pollution. Thus, the probability of observing statistically significant findings by chance is increased. However, Villeneuve and colleagues, ${ }^{32}$ in a study in Edmonton, Alberta, demonstrated an association between an increase in the interquartile range of the 5-day average of nitrogen dioxide and ozone in warm months and increased visits to the emergency department because of asthma attacks. These findings were similar to those observed in our study. In contrast, despite examining 6 pollutants, stratifying by sex and season, and exploring 3 lag periods, Szyszkowicz ${ }^{33}$ observed no association between air pollution and anxiety in 23178 visits to the emergency department in Edmonton. Thus, the association between air pollution and appendicitis may not have been entirely spurious. Nonetheless, future studies are necessary to replicate the findings in different populations.

\section{Conclusion}

Our findings indicate that some cases of appendicitis may be triggered by short-term exposure to air pollution. If these findings are confirmed, measures to improve air quality may decrease the rate of appendicitis.

This article has been peer reviewed.

\section{Competing interests: None declared.}

Contributors: Gilaad Kaplan and Paul Villeneuve contributed to the conception and design of the study and the analysis of the data. Elijah Dixon, Remo Panaccione, Andrew Fong and Steven Heitman contributed to the design of the study. Andrew Fong and Gilaad Kaplan developed the administrative dataset, which was validated by Elijah Dixon, Anthony MacLean, Donald Buie and Terry Leung. Li Chen, Mietek Szyszkowicz and Amanda Wheeler contributed to the analysis of data. Mietek Szyszkowicz, Amanda Wheeler, Elijah Dixon, Remo Panaccione, Anthony MacLean, Donald Buie and Steven Heitman contributed to the interpretation of the data. Gilaad Kaplan and Paul Villeneuve drafted the article, which was critically revised by the other authors. All of the authors approved the version submitted for publication.

Funding: No external funding was received for this research.

Acknowledgements: The authors thank Environment Canada for providing the data on air pollution from the National Air Pollution Surveillance Network. They also thank the Calgary Health Region for providing the administrative data on appendicitis cases and Kris Prepolec for proofreading the manuscript. Gilaad Kaplan is supported through a New Investigator Award from the Canadian Institutes of Health Research. Elijah Dixon is supported through a Population Health Investigator Award from the Alberta Heritage Foundation for Medical Research and a New Investigator Award from the Canadian Institutes of Health Research.

\section{REFERENCES}

1. Williams GR. Presidential Address: a history of appendicitis. With anecdotes illustrating its importance. Ann Surg 1983;197:495-506.

2. Carr NJ. The pathology of acute appendicitis. Ann Diagn Pathol 2000;4:46-58.

3. Addiss DG, Shaffer N, Fowler BS, et al. The epidemiology of appendicitis and appendectomy in the United States. Am J Epidemiol 1990;132:910-25.

4. Luckmann R, Davis P. The epidemiology of acute appendicitis in California: racial, gender, and seasonal variation. Epidemiology 1991;2:323-30.

5. Basta M, Morton NE, Mulvihill JJ, et al. Inheritance of acute appendicitis: familial aggregation and evidence of polygenic transmission. Am J Hum Genet 1990;46: 377-82.

6. Andersson R, Hugander A, Thulin A, et al. Clusters of acute appendicitis: further evidence for an infectious aetiology. Int J Epidemiol 1995;24:829-33.

7. Walker AR, Segal I. Is appendicitis increasing in South African blacks? S Afr Med $J$ 1979;56:503-4.

8. Raguveer-Saran MK, Keddie NC. The falling incidence of appendicitis. Br J Surg 1980;67:681.

9. Chen TM, Shofer S, Gokhale J, et al. Outdoor air pollution: overview and historical perspective. Am J Med Sci 2007;333:230-4.

10. Williams NM, Jackson D, Everson NW, et al. Is the incidence of acute appendicitis really falling? Ann R Coll Surg Engl 1998;80:122-4.

11. Brunekreef B, Holgate ST. Air pollution and health. Lancet 2002;360:1233-42. 
12. Villeneuve PJ, Chen L, Stieb D, et al. Associations between outdoor air pollution and emergency department visits for stroke in Edmonton, Canada. Eur J Epidemiol 2006;21:689-700.

13. Gorham ED, Garland CF, Garland FC. Acid haze air pollution and breast and colon cancer mortality in 20 Canadian cities. Can J Public Health 1989;80:96-100.

14. Schierhorn $\mathrm{K}$, Zhang M, Matthias C, et al. Influence of ozone and nitrogen dioxide on histamine and interleukin formation in a human nasal mucosa culture system. Am J Respir Cell Mol Biol 1999;20:1013-9.

15. Cho HY, Morgan DL, Bauer AK, et al. Signal transduction pathways of tumor necrosis factor-mediated lung injury induced by ozone in mice. Am J Respir Crit Care Med 2007;175:829-39.

16. Ayyagari VN, Januszkiewicz A, Nath J. Effects of nitrogen dioxide on the expression of intercellular adhesion molecule-1, neutrophil adhesion, and cytotoxicity: studies in human bronchial epithelial cells. Inhal Toxicol 2007:19:181-94.

17. Tornqvist H, Mills NL, Gonzalez M, et al. Persistent endothelial dysfunction in humans after diesel exhaust inhalation. Am J Respir Crit Care Med 2007;176:395400

18. Tsuji M, Puri P, Reen DJ. Characterisation of the local inflammatory response in appendicitis. J Pediatr Gastroenterol Nutr 1993;16:43-8.

19. Wang Y, Reen DJ, Puri P. Is a histologically normal appendix following emergency appendicectomy alway normal? Lancet 1996;347:1076-9.

20. Bittinger F, Brochhausen C, Kohler H, et al. Differential expression of cell adhesion molecules in inflamed appendix: correlation with clinical stage. J Pathol 1998; $186: 422-8$

21. Maclure $M$. The case-crossover design: a method for studying transient effects on the risk of acute events. Am J Epidemiol 1991;133:144-53.

22. Janes H, Sheppard L, Lumley T. Case-crossover analyses of air pollution exposure data: referent selection strategies and their implications for bias. Epidemiology 2005; $16: 717-26$

23. Ponka A, Virtanen M. Low-level air pollution and hospital admissions for cardiac and cerebrovascular diseases in Helsinki. Am J Public Health 1996;86:1273-80.

24. McGowan JA, Hider RN, Chacko E, et al. Particulate air pollution and hospital admissions in Christchurch, New Zealand. Aust N Z J Public Health 2002;26:23-9.

25. Hanninen OO, Palonen J, Tuomisto JT, et al. Reduction potential of urban PM2.5 mortality risk using modern ventilation systems in buildings. Indoor Air 2005;15: 246-56.

26. McConnell R, Berhane K, Yao L, et al. Predicting residential ozone deficits from nearby traffic. Sci Total Environ 2006:363:166-74.

27. Dybdahl M, Risom L, Moller P, et al. DNA adduct formation and oxidative stress in colon and liver of Big Blue rats after dietary exposure to diesel particles. Carcinogenesis 2003;24:1759-66.

28. Sigaud $\mathrm{S}$, Goldsmith $\mathrm{CA}$, Zhou $\mathrm{H}$, et al. Air pollution particles diminish bacterial clearance in the primed lungs of mice. Toxicol Appl Pharmacol 2007;223:1-9.

29. Ciencewicki J, Jaspers I. Air pollution and respiratory viral infection. Inhal Toxicol 2007; 19:1135-46.

30. Gowdy K, Krantz QT, Daniels M, et al. Modulation of pulmonary inflammatory responses and antimicrobial defenses in mice exposed to diesel exhaust. Toxicol Appl Pharmacol 2008;229:310-9.

31. Bickell NA, Aufses AH Jr, Rojas M, et al. How time affects the risk of rupture in appendicitis. J Am Coll Surg 2006;202:401-6.

32. Villeneuve PJ, Chen L, Rowe BH, et al. Outdoor air pollution and emergency department visits for asthma among children and adults: a case-crossover study in northern Alberta, Canada Environ Health 2007:6:40.

33. Szyszkowicz M. Air pollution and emergency department visits for depression in Edmonton, Canada. Int J Occup Med Environ Health 2007;20:241-5.

Correspondence to: Dr. Gilaad G. Kaplan, Assistant Professor, Division of Gastroenterology, Departments of Medicine and Community Health Sciences, University of Calgary, Teaching Research and Wellness Center, 6th floor, Rm. 6D17, 3280 Hospital Dr. NW, Calgary AB T2N 4N1; fax 403 592-5050; ggkaplan@ucalgary.ca

\section{How safe are your Prescriptions?}

The pharmacist just filled a prescription for Beth. This is the 6th pharmacy Beth has visited today.

\section{Anyone can make a photocopy.}

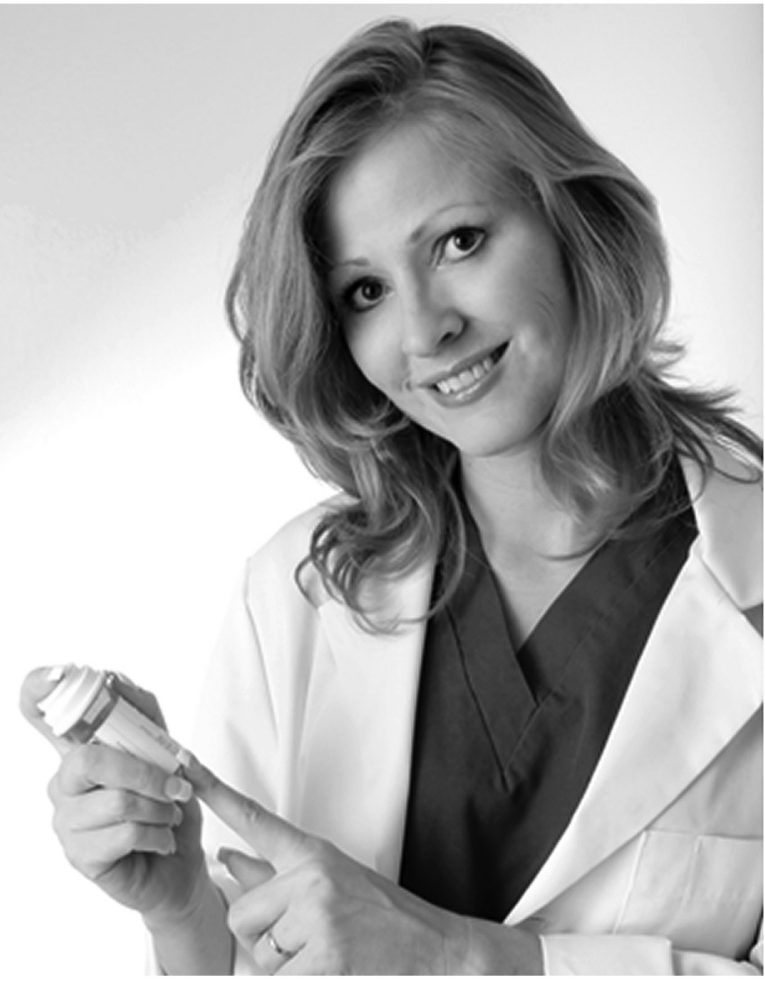

Call Rx Security today for your tamper-resistant prescription pads and EMR printer paper.

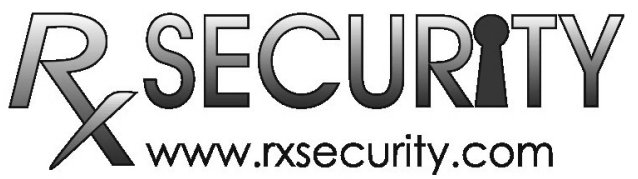

1-800-667-9723 www.rxsecurity.com 